\title{
Study on the Integrated Curriculum of Science and Technology Education
}

\author{
Zhao Yao, a , Chao Tu ${ }^{2, b}$ and Jun $\mathrm{Li}^{3, \mathrm{c}}$ \\ ${ }^{1}$ Changchun institute of engineering and technology, China \\ ${ }^{2}$ Changchun institute of engineering and technology, China \\ ${ }^{3}$ Changchun institute of engineering and technology, China \\ ayaozhao_1979@126.com, b332552083@qq.com
}

\section{Keywords: Modernization; Professional education; Military quality}

\begin{abstract}
In the process of modern military operations, the position of non-commissioned officers is very important, which bears the main training and operational needs of the troops. Therefore, the non-commissioned officers are required to have not only excellent professional knowledge, but also excellent practical ability and strong organizational training ability. However, the actual situation of military academy education is that the actual working ability of many cadets has not been greatly improved after graduation, and even some cadets' own military quality has been regressed. This paper conducts research on the connection between the theory and practice of modern noncommissioned officer professional technology education, hoping to further submit the level of connection between theory and practice, adjust the teaching idea and course setting, and lay a good foundation for students to go to their positions.

The training of modern high-quality new type of non-commissioned officer talents mainly depends on the non-commissioned officer school, and more importantly on rich new knowledge and strong practical ability. However point affected by education of our country for thousands of years of military culture, are still mainly rely on the traditional teaching method, teaching type or class of it plus miscellaneous also have part of the actual operation, but the actual effect, this kind of teaching model of "give priority to in order to teach", serious neglect students' actual operation ability, and is not able to improve the quality of the students more. Focus on the characteristics of the current officer vocational and technical, and actively explore more meet the requirements for modern noncommissioned officers and characteristics of talent training, should explore development in the new real integration programmes, to make students more faster to master a new skill, Accelerate the development of the army.
\end{abstract}

\section{The connotation of the integration course of theory and practice}

The practice of integrated course of military cadets' theory and practice is an appropriate combination of military theory and practice. But until now, the military academy has no very clear definition and standard for the integration of theory and practice education. However, the author's understanding of the connotation is as follows: to make full use of modern science and technology, integrate the main teaching contents such as theory, experiment and practical operation, organically combine classroom, training field and battlefield, and take the generation of knowledge imparting, skills training and practical ability as the main line of course design.

1. For subjects where theory and practice are relatively easy to combine, it is necessary to add as many as possible, and each teaching unit in the course is required to be operated by theory and practice. The best ratio is 1:1. This requires designers to be very familiar with the content of the class and understand how to apply it in practice.

2. If a certain knowledge point is too large in the teaching process, it is better to decompose several small modules and add corresponding practical operation to a certain module. In short, the teacher should add as many practical operation contents as possible to further enrich the classroom teaching contents. 
3. If the teaching content at a certain stage is mainly theoretical teaching, practical experience should be added as much as possible in the teaching process, teaching some examples and phenomena to further verify the authenticity of the theory.

4. If practical operation takes up a large proportion in the teaching process at a certain stage, theoretical traction practice should be added in the teaching process, and classroom teaching should be carried out by "doing middle school" to cultivate students' professional quality.

\section{The teaching principle of the integrated curriculum for noncommissioned officers}

1. Theoretical and practical teaching should be carried out alternately. Only when the two alternate, can the appearance of image and abstract staggered, can the student master the theory more solid, in turn can make the theory better guide the practice. Therefore, it should be exchanged once a day or once a week. The author feels that it is better to exchange once a day, because the knowledge points explained each day should not exceed 4 hours. If the time is too long, the previously learned knowledge can be easily forgotten, but the practice effect is not good.

2. Alternating order of theory and practice: it is possible to teach theory first or practice teaching first, but in the process of teaching implementation, teachers should constantly guide students to make knowledge summary, which should be carried out in the way of "theory - practice - theory" or "practice - theory - practice".

3. In the teaching process, students should be fully mobilized with their ears, hands, mouth and brain. Students are required to move their eyes and mouth to read a certain paragraph. During this process, students can also hear their own sound, which may be better than listening [3]. However, the teaching practice has proved that the private sector education students prefer to read the content of the textbook, and the teacher should ask and explain in a timely manner, then the classroom teaching effect will be very good.

Secondly, the teacher should ask questions in a timely manner. Once the teacher starts to ask questions, the students will be nervous and their attention will be relatively concentrated. This shows that asking questions is also a very important means to improve the classroom teaching effect.

Finally, practical operation is an important platform for training students' ability to use their hands and move their minds, testing whether students have a clear theoretical knowledge or not, and providing important support for the curriculum construction behind the teacher.

\section{The design of the teaching situation of the integrated curriculum of noncommissioned officer theory}

Modern sergeant vocational and technical education, especially the fire control system maintenance professional contains so many electronic devices, electronic technical innovation is very fast, intelligentize degree is high, and most petty officer cadets from the cultivation of the two years of academic knowledge, logical thinking is poorer, but most of the students' ability of interaction is stronger, like to operate. Therefore, the course content and the student's practice situation have some deviation, resulting in the student learning effect is poor. Then must design the reasonable teaching situation to adapt the student to raise the request.

1. Component level fault detection teaching scenario design

As part detection is the most basic and practical skill in the maintenance detection of cadets, it is very important for cadets to quickly detect and identify the problems of the parts they belong to to improve the rapid repair. Then, in the teaching process, we should talk more about the cases of component damage and the parts that often go wrong, as well as the common treatment methods for parts failure.

Students are allowed to analyze the failure caused by component damage, etc. [4][5]. In the teaching process, problems are often used to guide the corresponding teaching content, and the students are motivated to learn through the problems. 
2. Circuit board level fault detection scenario design

Let students understand the role of each circuit board in the components, as well as the damage and loss of each component will cause the fault phenomenon, these problems need to be guided in the teaching process.

3. Component - level fault detection scenario design

Component - level fault detection is more complex than that, requiring students to be very clear about the circuit board principles, understand the role of various components in the circuit board. Then, during the teaching process, the teacher can design some component faults in advance, guide the students to detect related devices, and should actively encourage the students to carry out device level detection, which will greatly promote the students' understanding of maintenance skills and knowledge.

\section{The teaching evaluation standard and examination of the integrated course of noncommissioned officer theory and practice}

The education course consists of a number of learning units and a process assessment ensures the quality of learning in each learning situation. Then the assessment process should be based on different content to set different standards.

1. Fault inspection and analysis

Excellent: it is reasonable to be able to quickly determine the cause of the fault and to analyze the cause of the fault.

Good: able to complete leading questions, analyze system failures, and answer questions correctly.

Pass the test: be able to operate under the guidance of the instructor, be able to analyze the failure point

2. Make maintenance plan

Excellent: able to make reasonable repair plan, able to understand flow chart, able to select appropriate maintenance tools.

Good: able to work out the corresponding maintenance plan reasonably.

Pass the test: be able to work out the repair plan under the guidance of the instructor.

3. Operation and implementation

Excellent: able to complete system fault detection and repair, no detour in the whole process, and can guide other trainees to detect.

Good: can basically complete system troubleshooting. The whole overhaul process is relatively smooth.

Passing: ability to perform troubleshooting under the guidance of the instructor.

\section{References}

[1] Wang Gang. Happenstance in science classroom [J]; Professional education; 06, 2002

[2] Li Xiaomei; What about occasional incidents in classroom teaching [J]; Shaanxi technology; 07, 2002

[3] Jiang Feng; Cases of classroom happenstance [J]; Education methodology; 03, 2005

[4] Li Wenjie. Open research on higher education learning courses [J]. Professional skills education, 2011

[5] Meng Xiugang. Generation and development of military talent quality [J]. Henan; Henan university press, 2001

[6] Zhou Qhuang. Analysis of design thought of modern tank fire control system [J]. Journal of military engineering (journal of tank armored vehicle and engine),1987.04 